Article

\title{
Dynamic Properties of Granulated Rubber Using Different Laboratory Tests
}

\author{
Ahmed Moussa ${ }^{1}$, Hany El Naggar ${ }^{1, *}$ and Abouzar Sadrekarimi ${ }^{2}$ \\ 1 Department of Civil and Resource Engineering, Dalhousie University, Halifax, NS B3H 4R2, Canada; \\ ahmed.moussa@dal.ca \\ 2 Department of Civil and Environmental Engineering, Western University, London, ON N6A 5B9, Canada; \\ asadrek@uwo.ca \\ * Correspondence: hany.elnaggar@dal.ca; Tel.: +1-902-494-3904
}

Citation: Moussa, A.; El Naggar, H.; Sadrekarimi, A. Dynamic Properties of Granulated Rubber Using Different Laboratory Tests. Buildings 2021, 11, 186. https://doi.org/10.3390/ buildings 11050186

Academic Editor: Lukasz Sadowski

Received: 14 March 2021

Accepted: 25 April 2021

Published: 28 April 2021

Publisher's Note: MDPI stays neutral with regard to jurisdictional claims in published maps and institutional affiliations.

Copyright: (c) 2021 by the authors. Licensee MDPI, Basel, Switzerland. This article is an open access article distributed under the terms and conditions of the Creative Commons Attribution (CC BY) license (https:// creativecommons.org/licenses/by/ $4.0 /)$.

\begin{abstract}
Due to the socio-environmental hazards arising from the stockpiling of disposed scrap tires, the necessity to utilize such material in civil construction and other applications is deemed mandatory. The lightweight of rubber and its high damping capacity are excellent properties of a geomaterial that could be used successfully in seismic isolation and vibration damping applications in civil construction. Scrap tires could be shredded into specific sizes, and their category and application depend on their particle size range. Thus, understanding the dynamic properties and behavior of shredded scrap tires under cyclic loading is of paramount importance. In this study, the dynamic characteristics of granulated rubbers $(<12 \mathrm{~mm})$ are investigated using cyclic triaxial and cyclic direct simple shear tests. The effect of using different testing techniques, i.e., cyclic triaxial test (CTT) and cyclic simple shear test (CSST), on the dynamic properties of granulated rubber material is further addressed. Undrained cyclic triaxial and constant-volume direct simple shear tests are conducted on granulated rubber samples under vertical consolidation stresses of 25, 50, 100 and $200 \mathrm{kPa}$ at a frequency of $0.5 \mathrm{~Hz}$. The shear strain amplitude is varied from $0.01 \%$ to $10 \%$. Furthermore, the variations of shear modulus and damping ratio with shear strain amplitude are presented. In addition, the obtained dynamic properties from this study are compared with existing experimental data from the literature. It was found that the ranges of shear moduli of granulated rubber from the CTT and CSST are 278 to $2647 \mathrm{kPa}$ and 85 to $2270 \mathrm{kPa}$, respectively. Moreover, the damping ratios obtained from CTT were higher than those from CSST at shear strains of less than $1 \%$. The damping ratio of granulated rubber was also found to be independent of the vertical consolidation stress.
\end{abstract}

Keywords: cyclic triaxial test; cyclic direct simple shear test; granulated rubber

\section{Introduction}

Due to the substantial increase in the disposal of scrap tires worldwide, millions of scrap tires are sent to stockpile or landfills. These actions raise a great concern regarding the safety of the environment and human health. Stockpiling or landfilling of scrap tires could cause several environmental and health hazards such as fire hazards, a breeding ground for insects, and contaminating underground water. Therefore, reusing scrap tires has become an important necessity to reduce their impact on the environment and public health.

In order to use scrap tires in civil engineering applications, scrap tires have to be shredded into smaller pieces. This shredding process results in different particle size ranges of shredded tires. According to ASTM D6270 [1], the particles sizes are classified into seven categories: (1) powdered rubber, (2) ground rubber, (3) granulated rubber, (4) tire chips, (5) tire shreds, (6) Tire Derived Aggregates (TDA) and (7) rough shreds.

Reusing scrap tires in civil engineering applications as a geotechnical material has gained wide popularity due to its versatile geotechnical properties. For example, TDA has been proven to be an excellent geotechnical material as a stress-reduction fill over preexisting buried pipes and as a lightweight backfill material under shallow foundations [2-7]. 
Furthermore, due to its outstanding attenuation capacity, it could be used to improve the seismic performance of retaining walls and mitigate ground vibrations [8,9]. For example, $\mathrm{Ni}$ et al. [10] found that using TDA could increase the buried pipeline critical fault offset capacity by $20 \%$. Also, Xiao et al. [11] showed that MSE walls with reinforced TDA backfill outperformed those with regular soil backfill under seismic conditions. Moreover, Ahn and Cheng [12] examined the performance of TDA-backfill finite element model for a semi-gravity reinforced-concrete cantilever retaining wall subject to the Takatori earthquake. It was concluded that the TDA backfill resulted in significantly less acceleration amplification at the backfill surface. Thus, the geotechnical properties of TDA have been extensively investigated recently to accurately predict its behavior under dynamic and static loads [13-21].

Several researchers have conducted dynamic and cyclic laboratory soil tests to investigated the dynamic characteristics of granulated rubber using different tests. For example, Feng and Sutter [21] obtained the shear modulus and damping ratio for a granulated rubber material that has a particle size range of 2.00 to $4.76 \mathrm{~mm}$ using a resonant column test. Moreover, Hazarika et al. [22] performed cyclic triaxial tests to investigate the granulated rubber behavior under cyclic loading. It was found that its behavior under cyclic loading was viscoelastic. In addition, mixing parent soil with tire chips could prevent liquefaction if a proper percentage of tire chips were used. Similarly, Madhusudhan et al. [21] performed cyclic triaxial tests under a wide range of shear strains to calculate the shear modulus and damping ratio of pure granulated rubber and sand-rubber mixtures. It was found that a sand-rubber mixture containing $10 \%$ rubber could be used effectively for seismic base isolation of low-rise buildings. In addition, Sarajpoor et al. [23] used dynamic hollow cylinder tests to investigate the various parameters that could affect granulated rubber and sand-rubber mixtures behavior under dynamic loads.

Based on the studies mentioned above, the obtained dynamic properties of granulated from different tests could vary. Thus, it is important to highlight and understand the extent of the effect of using a different laboratory test to obtain shear modulus and damping ratio values. To the best of the authors knowledge, this issue has not been addressed yet for the granulated rubber material. Therefore, the following paragraph briefly shows the effect of using different laboratory tests on the obtained dynamic properties of conventional soil.

Cavallaro et al. [24] conducted various laboratory tests on undisturbed clay samples to find their dynamic properties (i.e., soil stiffness and damping). The dynamic investigations were carried out in the laboratory using Resonant Column Test (RCT), Cyclic Torsional Shear Test (CTST) and Double Specimen Cyclic Simple Shear Test (DSCSS). The results showed that at low and intermediate shear strain, there was a significant difference between stiffness obtained from the RCT and DSCSS. While, the shear modulus obtained from CTST was in-between the RCT and DSCSS. Similarly, damping ratios obtained from RCT were consistently higher than those obtained from CTST and DSCSS. Another investigation by Cavallaro et al. [23] was carried out to obtain the dynamic parameters for undisturbed clay samples using RCT, CTST and Cyclic Triaxial Test (CTT). It was concluded that the normalized shear modulus curves obtained from RCT and CTST were in a good agreement with each other. Whereas, the normalized shear modulus curve obtained from CTT showed a significant shear modulus degradation rate than those obtained from RCT and CTST. Furthermore, the damping ratios obtained from RCT were significantly greater than those obtained from CTST, while, the difference between RCT and CTT results was negligible.

Furthermore, Subramanian and Banerjee [25] conducted RCTS and CTSTs on cementtreated marine clay to investigate the variation of the obtained shear modulus and damping ratios. Similar to the findings of Cavallaro et al. [24,26], the shear modulus obtained from RCTs were higher than those from CTSTs. Moreover, the damping ratios calculated from RCTs and CTSTs did not vary significantly. On the other hand, when the cement content increased to $10 \%$, there was a significant variation between both tests. Furthermore, Bedr et al. [27] investigated the shear modulus and damping ratio of Algiers Marls. A variety of laboratory testing apparatuses were used to conduct this investigation (i.e., 
CTT, DSCSS, CTST and RCT). The calculated normalized shear modulus curves from RCTs showed a rapid shear modulus degradation compared to the CTST and DSCSS. Furthermore, there was no significant variation observed in the damping ratios calculated from all the test apparatuses.

All the above-mentioned research studies indicate that using different testing techniques could lead to a significant variation in dynamic parameters. Hence, this paper aims to investigate the effect of using cyclic triaxial test (CTT) and cyclic simple shear test (CSST) in determining shear modulus and damping ratio. The output of this work is further compared with other published work regarding the dynamic properties of granulated rubber.

\section{Tested Material and Test Apparatuses}

\subsection{Tested Material}

The granulated rubber used herein was supplied by Atlantic Rubber Paving Inc. Figure 1 shows the gradation curve for the used material. The size of the granulated rubber ranges from 2.83 to $4.76 \mathrm{~mm}$. Furthermore, its uniformity $(\mathrm{Cu})$ and curvature $(\mathrm{Cc})$ coefficients are 1.43 and 0.97, respectively. According to ASTM D6270 [1] classification of tire shreds, the material used falls in the category of granulated rubber, which has a particle size range of 0.425 to $12 \mathrm{~mm}$.

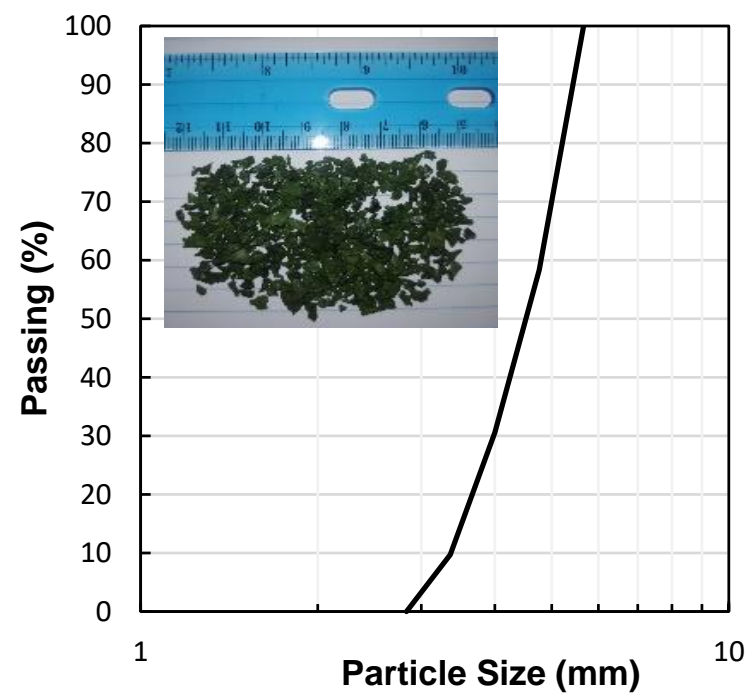

Figure 1. Gradation curve for granulated rubber.

\subsection{Cyclic Triaxial Apparatus}

Figure 2 shows components of the triaxial testing equipment used in this study. The triaxial cell can accommodate a sample size of $70 \mathrm{~mm}$ in diameter and $150 \mathrm{~mm}$ in height. The resulting height to diameter ratio of 2 is consistent with the ASTM D3999 [25] recommendation. Furthermore, two pressure-volume controllers were used to measure and control the cell pressure and pore-water pressure. Additionally, the axial deviatoric load was applied using an Instron 8501 hydraulic loading frame. An external load cell and a linear variable displacement transducer (LVDT) were attached to the load frame to measure the deviatoric load and axial displacement of the specimen. 


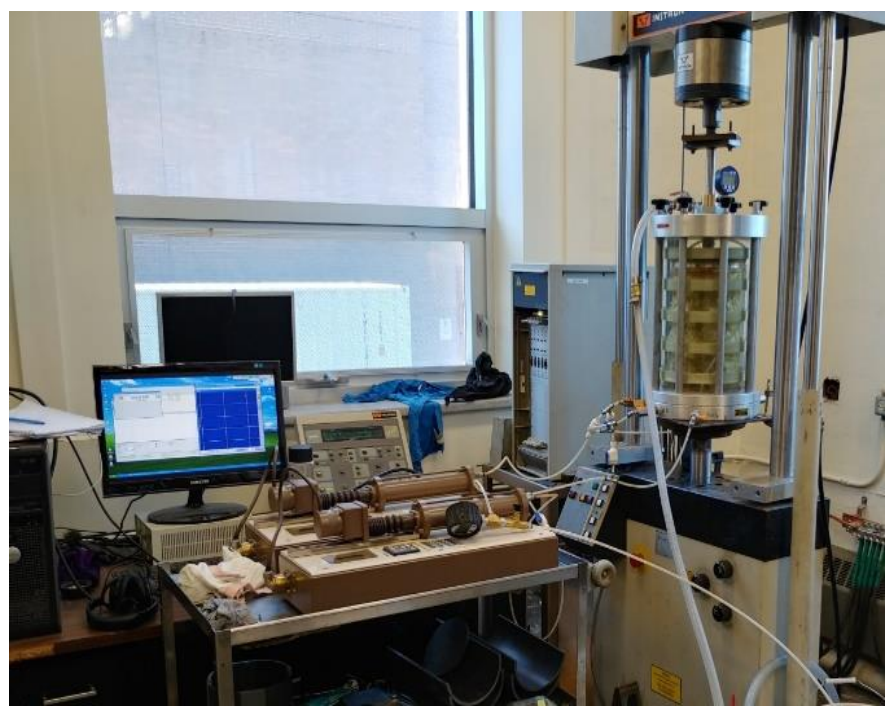

Figure 2. Cyclic triaxial test set up, adapted from Moussa and El Naggar [9].

\subsection{Cyclic Simple Shear Test}

A cyclic direct simple shear (DSS) device manufactured by GDS Instruments was used to conduct the cyclic simple shear tests. This apparatus can accommodate a specimen size of $70 \mathrm{~mm}$ in diameter and up to $28.1 \mathrm{~mm}$ high inside 26 Teflon coated steel rings. Each steel ring has a thickness of $1.1 \mathrm{~mm}$. However, before placing the granulated rubber, a latex membrane was used to cover the inside circumference of the specimen mold. Figure 3 shows the cyclic DSS device used and a mounted specimen inside the steel rings. Two porous stainless-steel discs with sharp concentric teeth were placed at the top and bottom of the specimen to transfer the shear load to the specimen. A $2 \mathrm{kN}$ load cell and 2 LVDTs (with a range of $\pm 10 \mathrm{~mm}$ ) are used to measure shear and normal forces and displacements of the specimen.

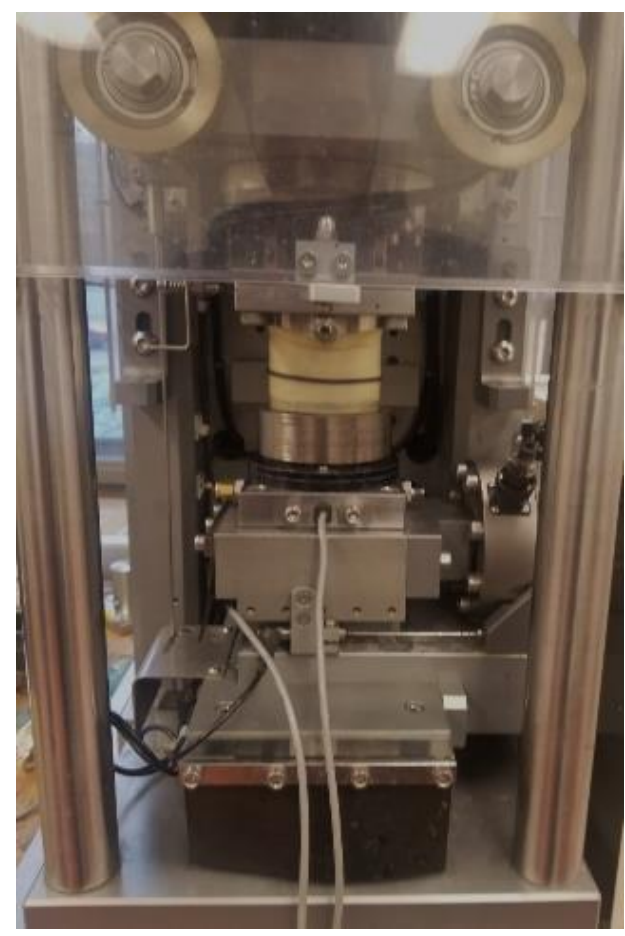

Figure 3. A DSS specimen mounted for testing. 


\section{Testing Program and Sample Preparation}

\subsection{Testing Program}

Multi-stage loading undrained cyclic triaxial tests were carried out in this study under strain-controlled conditions. The confining pressures $\left(\sigma_{\mathrm{c}}\right)$ used herein were 25 , 50 and $100 \mathrm{kPa}$, and the shear strain $(\gamma)$ amplitude varied from 0.1 to $10 \%$. Each stage corresponds to a certain shear strain amplitude; however, the confining pressure was kept constant throughout all the stages for each test. As stated by the ASTM D3999 [28] standard for determining modulus and damping properties of soils, no generation of excess pore water pressure is allowed between each stage; therefore, 20 cycles with extremely small axial stains were applied between the stages to dissipate any excess pore water pressure generated between each stage.

Multi-stage loading cyclic simple shear tests (CSST) were also conducted similar to the CTT. However, since the DSS device was able to capture smaller shear strain amplitudes, the shear strain amplitudes for the CSST varied from 0.01 to $10 \%$. Furthermore, the vertical stresses $\left(\sigma_{\mathrm{v}}\right)$ used were $25,50,100$ and $200 \mathrm{kPa}$ corresponding to vertical stress levels on buried pipelines, culverts, or shallow foundations.Table 1 summarizes the testing scheme used in this study. Both C.T.T. and CSST tests were performed at a cyclic loading frequency of $0.5 \mathrm{~Hz}$.

Table 1. Summary of the testing program.

\begin{tabular}{cccc}
\hline Table & $\begin{array}{c}\gamma \\
(\mathbf{\%})\end{array}$ & $\begin{array}{c}\boldsymbol{\sigma}_{\mathbf{c}}^{\prime} \text { or } \boldsymbol{\sigma}_{\mathbf{v c}}^{\prime} \\
\mathbf{( k P a )}\end{array}$ & No. of Cycles Per Stage \\
\hline CTT & $0.1,1,2,5,7.5,10$ & $25,50,100$ & Stage one: 100 \\
CSST & $0.01,0.05,0.1,1,2,5,7.5,10$ & $25,50,100,200$ & Other Stages: 50 \\
\hline
\end{tabular}

\subsection{Sample Preparation}

Because of the large specimen size, CTT specimens were prepared by tamping granulated rubber in five layers in the specimen mold. Each layer was compacted by 20 blows of the tamping rod. All specimens were prepared in a dry condition as the dry density of the TDA is not significantly influenced by introducing water [29]. In addition, all specimens were saturated until Skempton's pore pressure coefficient (B-value) became greater than 0.97 .

The CSST specimens was also compacted using a tamping rod; however, since the height of the specimen was only $28.1 \mathrm{~mm}$, the granulated rubber material was placed in three layers instead of five, and each layer was compacted by 25 blows of the tamper. Furthermore, all specimens were flushed with water until there was almost no air trapped inside the specimens.

\section{Results and Discussion}

Due to the enormous amount of data obtained from both CTT and CSST, a MATLAB code was developed to process and calculate the dynamic properties of the granulated rubber material. The obtained data from CCT are a series of hysteretic stress-strain curves, an example of which is shown in Figure 4a. The procedure presented by ASTM D3999 [28] was adapted to calculate the shear modulus $(G)$ and damping ratio $(\xi)$ from the hysteretic stress-strain curves. On the other hand, the output of CSST is a series of hysteretic shear stress-shear strain curves, and an example is shown in Figure $4 \mathrm{~b}$. 


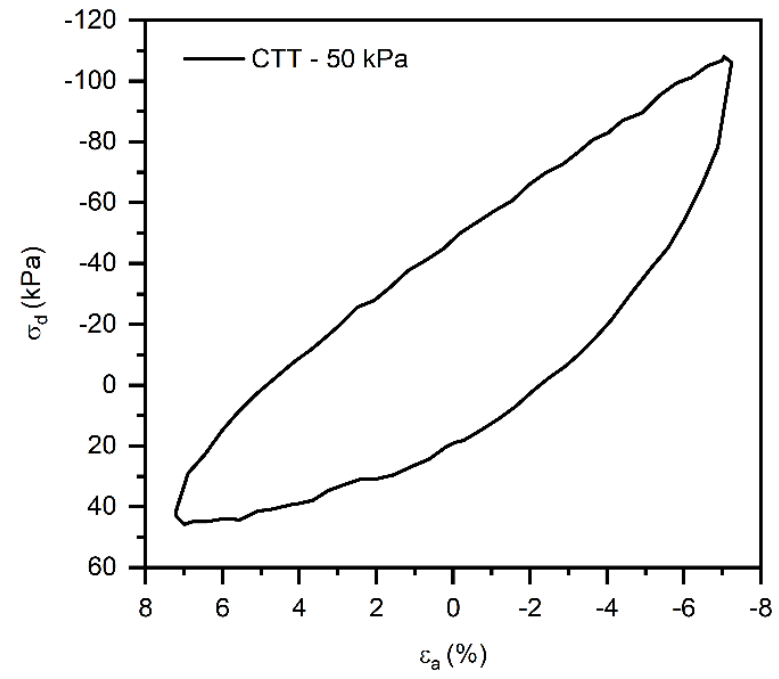

(a)

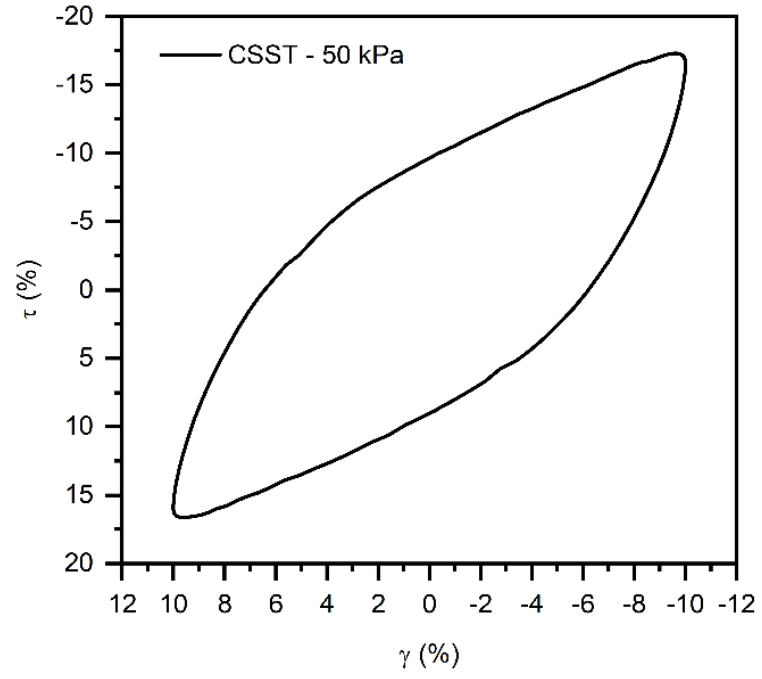

(b)

Figure 4. Hysteretic loops at $\gamma=10 \%$ from (a) CTT and (b) CSST.

\subsection{Backbone Curves}

The backbone curves for both tests were obtained by plotting the maximum and minimum shear stress versus the maximum and minimum shear strain from a specific hysteretic loop at each strain level. In the present study, the 10th hysteretic loop was used to plot the backbone curves (Figure 5). Figure 6 shows the backbone curves for the CTT and CSST at consolidation stresses of 25,50 and $100 \mathrm{kPa}$. The following equations were used to convert the deviatoric stress and axial strain from the CTT to shear stress $(\tau)$ and shear strain $(\gamma)$ :

$$
\begin{gathered}
\tau=0.5 \sigma_{\mathrm{d}} \\
\gamma=\frac{3}{2} \varepsilon_{\mathrm{a}}
\end{gathered}
$$

where $\sigma_{\mathrm{d}}=$ effective deviatoric stress, and $\varepsilon_{\mathrm{a}}=$ axial strain.

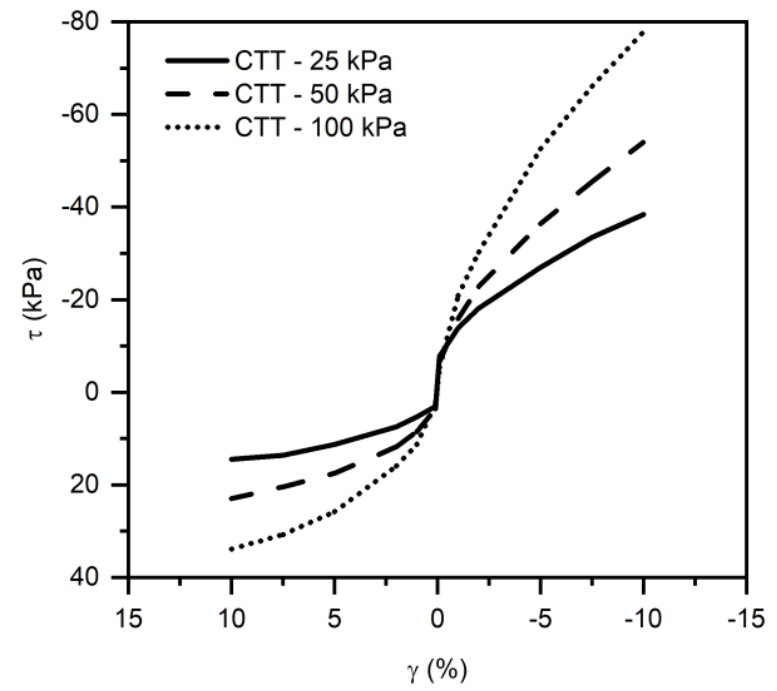

(a)

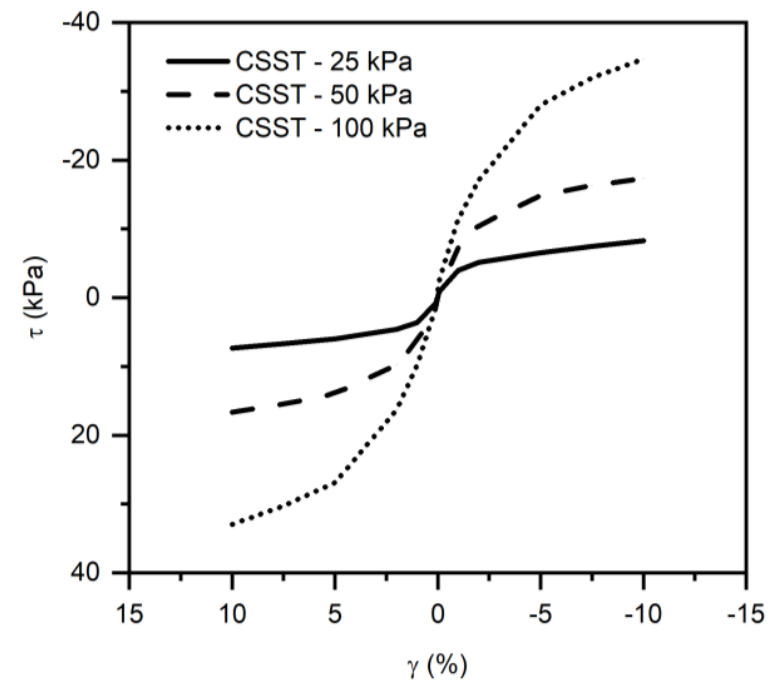

(b)

Figure 5. Backbone curves at different consolidation stresses from (a) CTTs and (b) CSSTs tests. 


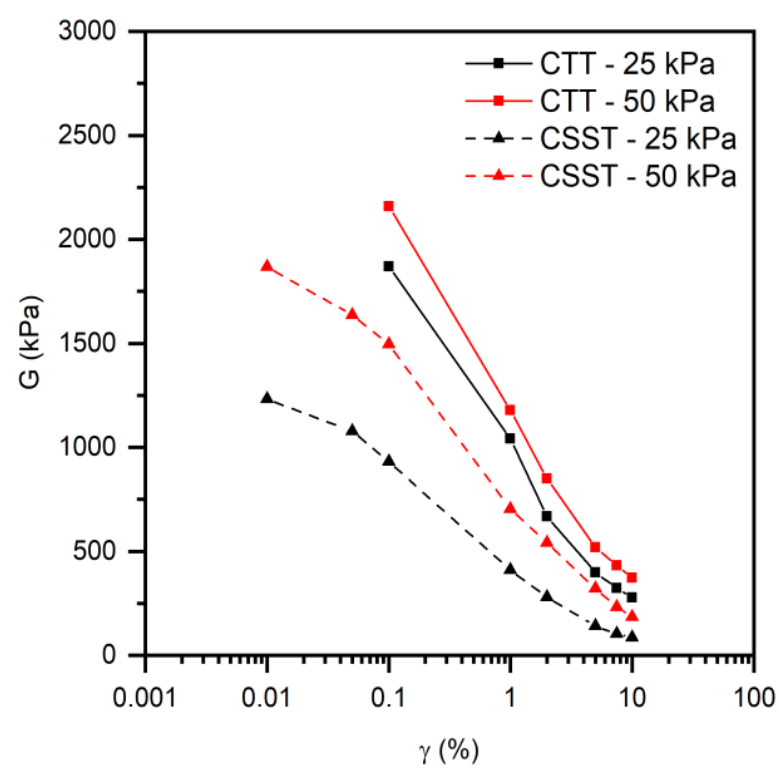

(a)

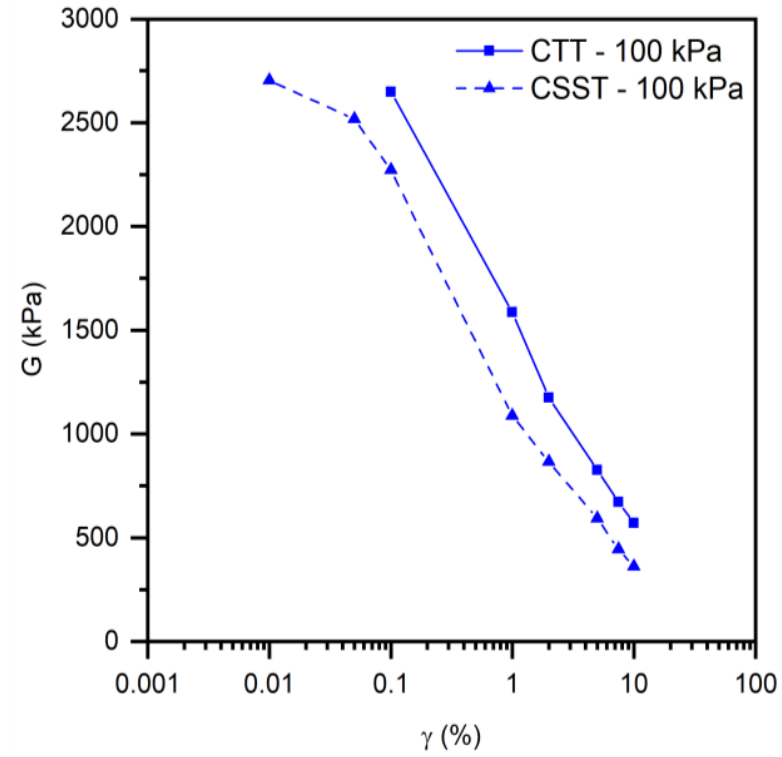

(b)

Figure 6. Comparisons of shear modulus with shear strain amplitude under consolidation stresses of (a) 25 and $50 \mathrm{kPa}$, and (b) $100 \mathrm{kPa}$.

As shown in Figure 5 the backbone curves obtained from CTT tests show that the granulated rubber behaves almost like a bilinear material with a slight nonlinearity under all confining pressures. Moreover, none of the CTT backbone curves are symmetric with respect to the origin, which is expected since the hysteretic loop was not symmetric as well, as shown in Figure 5a. This is because of the anisotropic stiffness of granulated rubber, being higher in compression than in extension.

In contrast, the backbone curves obtained from CSST tests show more significant nonlinearity under all vertical stresses in comparison to those plotted from CTTs. Additionally, all curves are symmetric about the origin. However, none of the backbone curves obtained from either CTT or CSST tests show a peak shear stress even at a high strain level (i.e., $10 \%)$.

\subsection{Shear Modulus}

Shear modulus was calculated for both tests from the 10th cycle at each shear strain level for all consolidation stresses. Figure 7 shows the variations of shear modulus with shear strain amplitude for consolidation stresses of 25, 50 and $100 \mathrm{kPa}$. In general, it could be observed that as shear strain increases, the shear modulus decreases nonlinearly. Despite the similar ranges of shear moduli from both tests, shear moduli at a given consolidation stress are significantly different between both tests.

As indicated in Figure 6, the difference in shear moduli from CTT and CSST is the highest at a small shear strain amplitude of $0.1 \%$. This is likely because of the different shear plane orientations with respect to the orientation of the rubber particles in these two tests. Shearing occurs mostly along the rubber particles in the CSST tests, while the shearing direction crosses through the rubber particles in the CTT tests and thus mobilizes their pull-out resistance resulting in higher shear moduli. However, as the shear strain amplitude increases, this difference decreases. This could be due to stiffness degradation at higher shear strains. So as the material is subjected to higher shear strains, it loses most of its stiffness, and thus the difference between the calculated shear moduli from both tests is reduced. Furthermore, this difference in shear moduli is larger at the low consolidation stress of $25 \mathrm{kPa}$. 


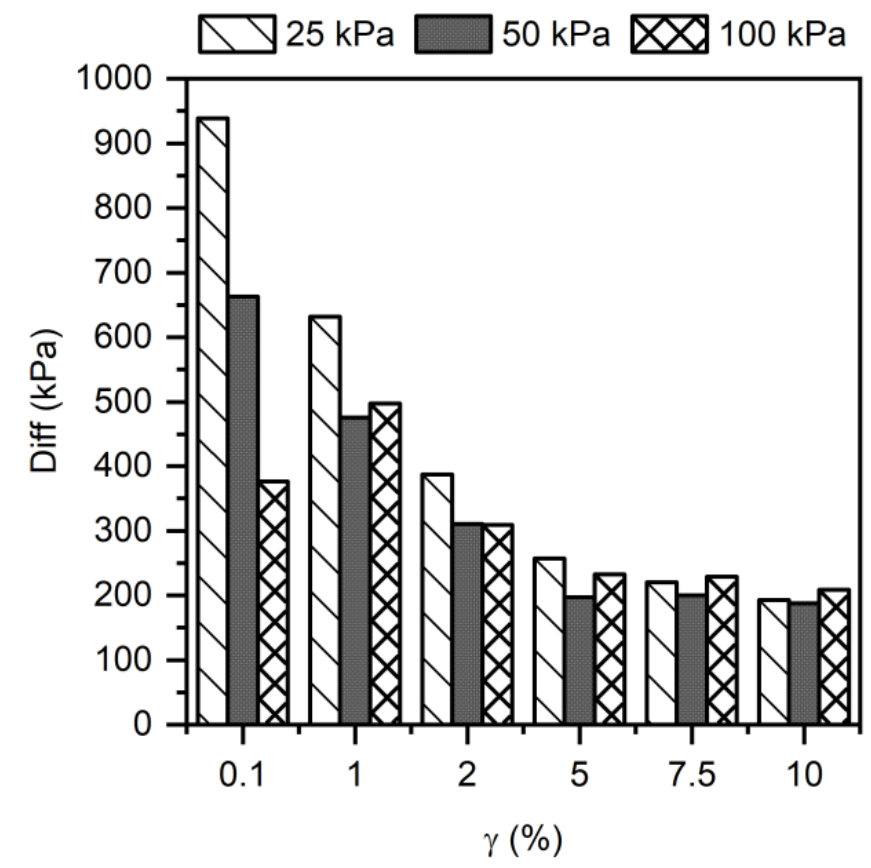

Figure 7. Variation between the shear modulus values obtained from CTT and CSST.

\subsection{Damping Ratio}

Damping ratios obtained from CTT and CSST tests are compared in Figure 8. According to this figure, the damping ratios calculated from CTT at shear strains of less than or equal to $1 \%$ under all confining stresses are dramatically larger than those determined from CSST tests. However, at higher shear strains, the difference between damping ratios from both tests reduces. In addition, both tests indicate that the granulated rubber's damping ratio is independent of the consolidation stress.

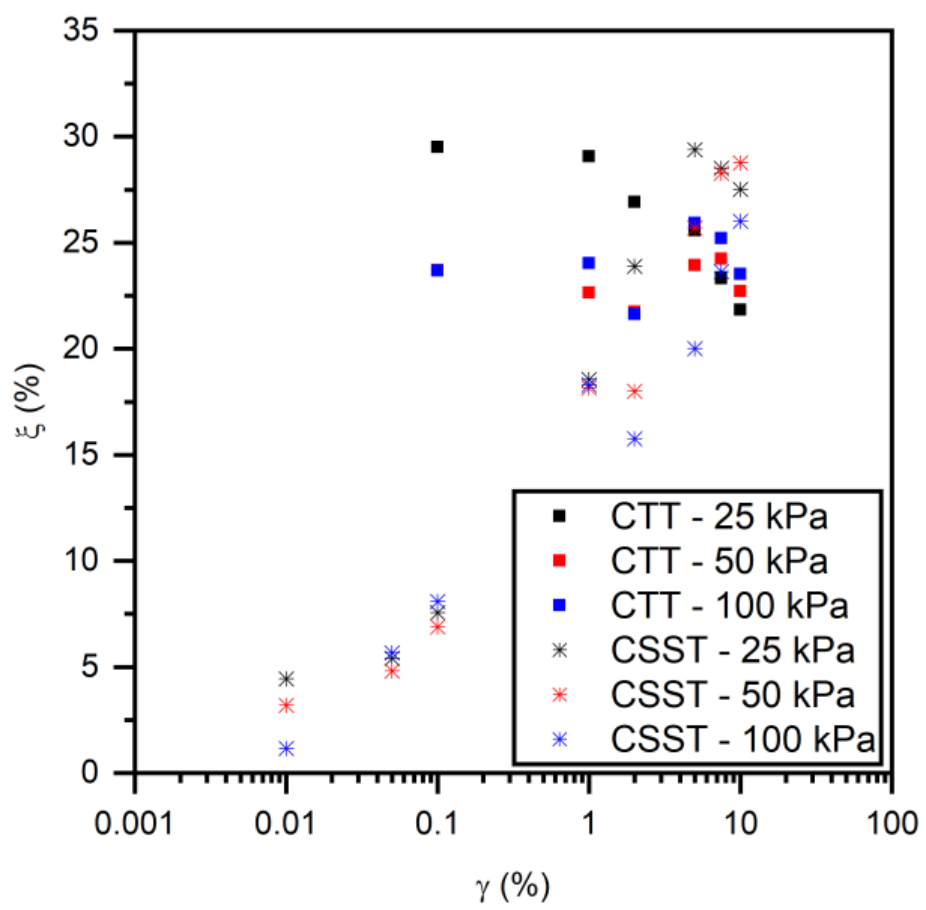

Figure 8. Comparison of damping ratios with shear strain amplitude from CTT and CSST. 


\subsection{Comparison of Dynamic Properties with Those from Literature}

Feng and Sutter [21] conducted resonant column tests on granulated rubber material with a particle size range of 2 to $4.76 \mathrm{~mm}$. The consolidation pressure and shear strain ranged from 69 to $483 \mathrm{kPa}$ and 0.0035 to $0.09 \%$, respectively. The results of these resonant column tests at $\sigma_{\mathrm{v}}^{\prime}=207 \mathrm{kPa}$ are compared with a CSST test of this study at $\sigma^{\prime}{ }_{\mathrm{v}}=200 \mathrm{kPa}$ in Figure 9. It is clear that there is a significant discrepancy between the shear moduli obtained from both tests. Such difference between shear moduli from resonant column and CSST tests has also been observed in the testing of natural sediments [27]. This could be due to the difference in the strain rate and the number of cycles used in RCT and CSST tests. On the other hand, damping ratios calculated from both tests are in a good agreement with each other, especially at shear strain levels of $0.034 \%$ and $0.044 \%$.

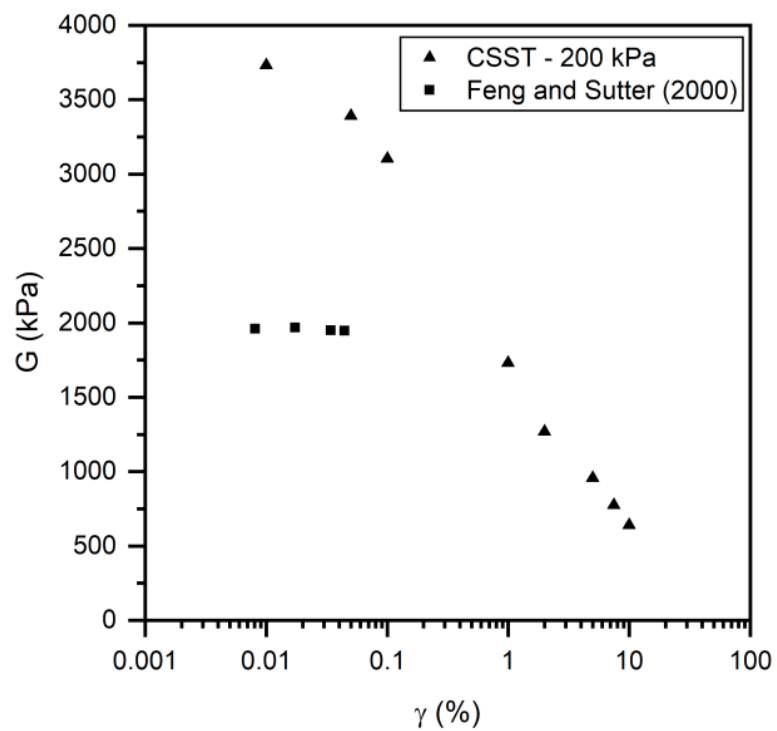

(a)

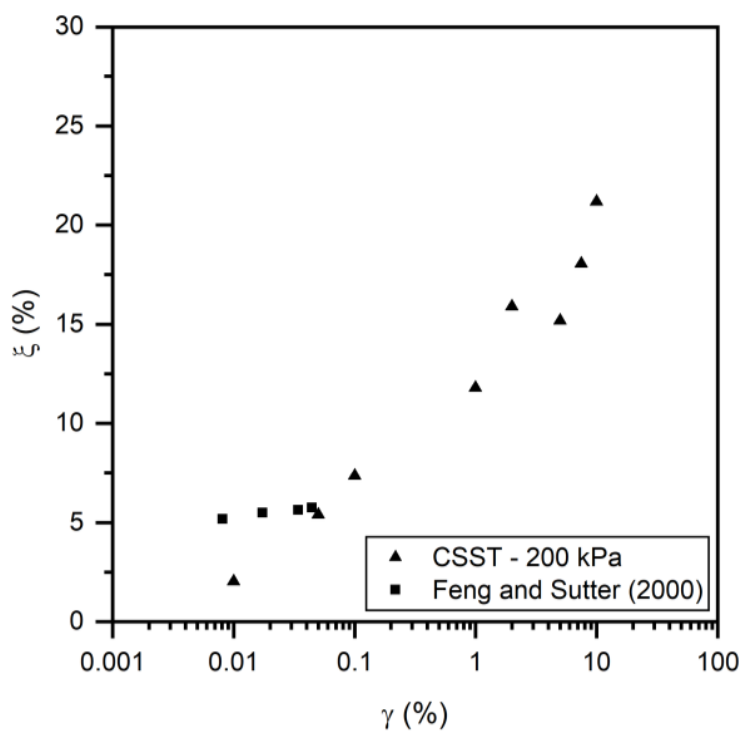

(b)

Figure 9. Comparisons between the (a) shear moduli and (b) damping ratios of CSSTs and Feng and Sutter [21].

The CTT and CSST results of the present study are further compared in Figure 10 with those obtained by Madhusudhan et al. [30] and Sarajpoor et al. [23] at a consolidation stress of $100 \mathrm{kPa}$. Madhusudhan et al. [21] conducted CTT tests on a granulated rubber material with particle sizes of less than or equal to $2 \mathrm{~mm}$. In addition, Sarajpoor et al. [23] conducted dynamic hollow cylinder tests on sand-rubber mixtures as well as a pure granulated rubber. The granulated rubber particle sizes were between 3.9 and $6.0 \mathrm{~mm}$.

As shown in Figure 10, shear moduli obtained from these tests are in a very good agreement with those of this study. Similarly, at low shear strain amplitudes (i.e., $<1 \%$ ), damping ratios obtained from the CSST tests are close to those reported by Madhusudhan et al. [30] and Sarajpoor et al. [23]. Nevertheless, there are significant variations and differences in damping ratios at shear strain amplitudes larger than $1 \%$. Some factors which could cause fluctuation in the damping ratios are the specimen preparation technique, sample size, aggregates size and the loading pattern.

Furthermore, the behavior of pure granulated rubber is compared to the behavior of natural soil and sand-rubber mixtures. Anastasiadis et al. [31] and Senetakis et al. [32] conducted several RCT on pure granulated rubber and sand-rubber mixtures. The obtained results from Anastasiadis et al. [31] and Senetakis et al. [32] are compared with the obtained results herein as shown in Figure 11 where R3, Parent Sand (C2D03), and R3-65/35 refer to pure rubber $\left(\mathrm{D}_{50}=2.9 \mathrm{~mm}\right)$, pure sand and a mixture of sand and rubber with a rubber content of $35 \%$ by weight, respectively. Note that the maximum shear moduli were obtained at shear strain levels of $0.01 \%$ and $0.1 \%$ in the CSST and CTT experiments of this study, while those reported by Anastasiadis et al. [31] and Senetakis et al. [32] correspond to shear 
strains of $1.15 \times 10^{-4 \%}$ to $4.6 \times 10^{-3 \%}$. According to Figure $11 \mathrm{a}$, the shear modulus of granulated rubber is significantly lower than that of pure soil and sand-rubber mixture, indicating the reduction of stiffness due to the inclusion of granulated rubber. In addition, similar to the findings by Feng and Sutter [19], $G_{\max }$ from RCT are lower than those from CSST and CTT tests. Figure $11 \mathrm{~b}$ further demonstrates that adding $35 \%$ of granulated rubber by weight to sand results in damping ratios almost identical to those obtained from the CSST of this study. Nevertheless, the highest damping ratios are obtained from the CTT tests.

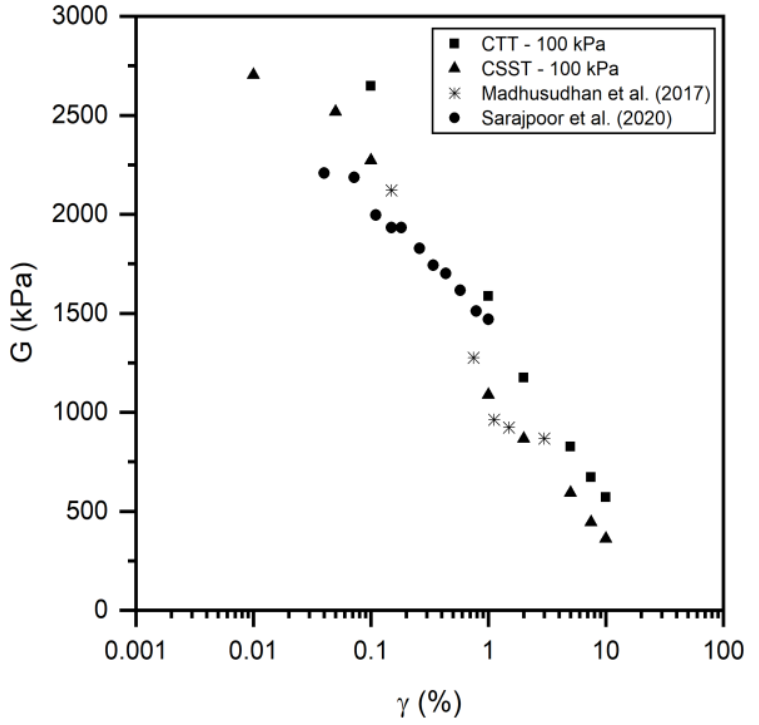

(a)

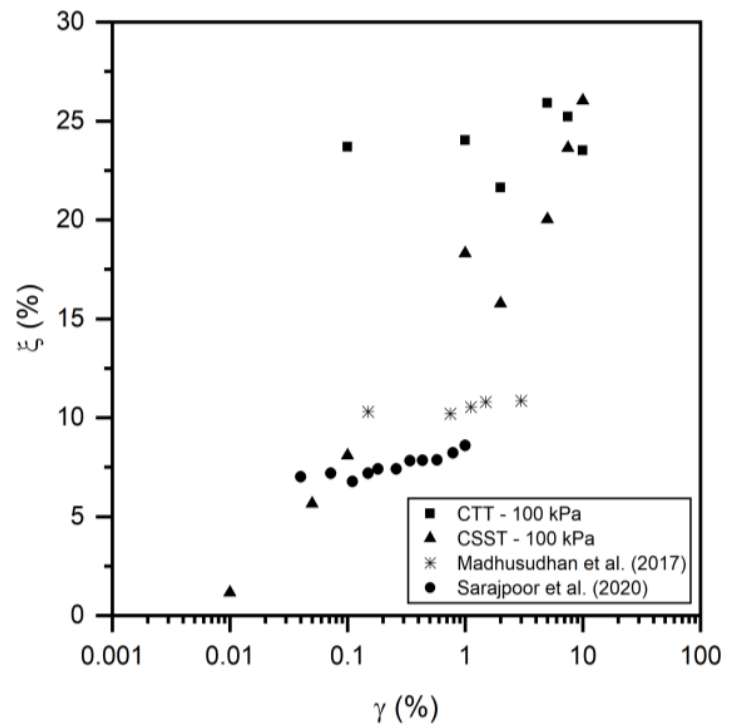

(b)

Figure 10. Comparisons of the (a) shear moduli and (b) damping ratios obtained from the CTTs and CSSTs in this study, with those from Madhusudhan et al. [30] and Sarajpoor et al. [23].

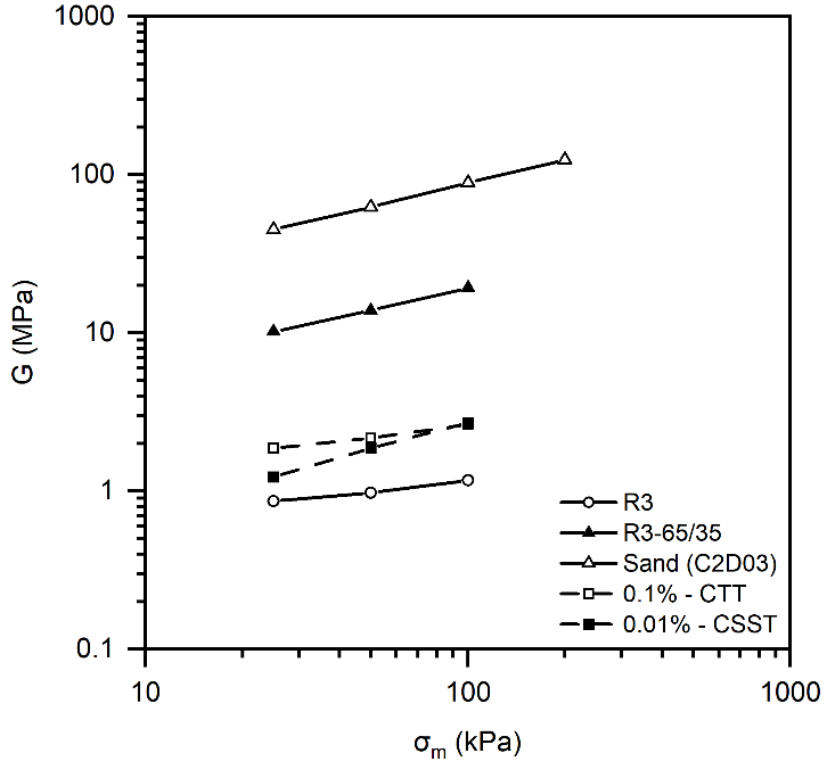

(a)

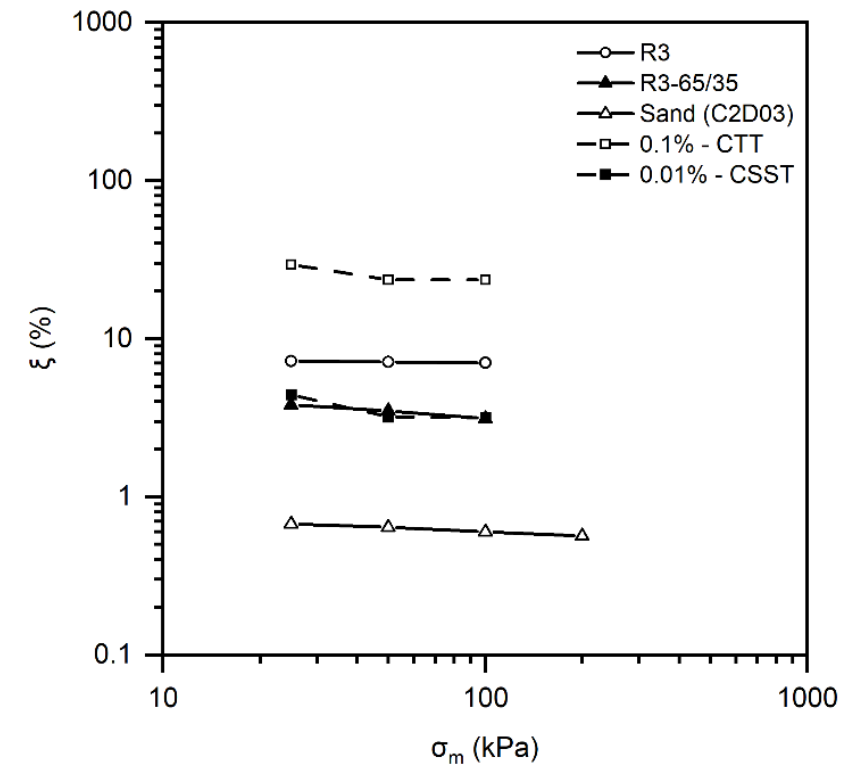

(b)

Figure 11. Relation between vertical consolidation stresses and (a) shear moduli and (b) damping ratios. 


\section{Conclusions}

Cyclic triaxial and cyclic simple shear tests were carried out in this study to investigate the effect of different laboratory testing methods on the shear modulus and damping ratio of a granulated rubber material. The confining pressures and shear strain amplitudes range for the CTT were 25 to $100 \mathrm{kPa}$, and 0.1 to $10 \%$, respectively. Whereas, vertical stresses and shear strain amplitudes considered for CSST were respectively 25 to $200 \mathrm{kPa}$, and 0.01 to $10 \%$. Based on the obtained results and comparisons with the literature, the following conclusions are made:

- The backbone curves plotted from the CTT indicate that the behavior of granulated rubber under cyclic loading could be simulated by a bilinear material model. However, the backbone curves plotted from CSST show that the behavior of the material is nonlinear under cyclic loading.

- Shear moduli obtained from the CTT and CSST ranged from 278 to $2647 \mathrm{kPa}$ and from 85 to $2270 \mathrm{kPa}$, respectively.

- As shear strain increased, the difference between the obtained shear moduli from both tests decreased.

- At low shear strain amplitudes (i.e., $0.1 \%$ ), damping ratios calculated from CTT are significantly larger than those from CSST.

- Damping ratios of granulate rubber material obtained from both tests were independent of consolidation stress.

- Comparison with the literature showed that the damping ratios of granulated rubber could be significantly different from one testing technique to another. Thus, investigating the damping ratio of rubber material using different techniques is recommended.

- The shear modulus values obtained from the dynamic hollow cylinder test, CSST and CTT are in good agreement with each other. Conversely, the results obtained by RCT were significantly different than the results of CSST, which could be attributed to the strain rate and the number of cycles used.

- Dynamic properties of granulated rubber could vary significantly from one test to another.

Author Contributions: Conceptualization, H.E.N.; Data curation, A.M.; Investigation, H.E.N., A.S.; Supervision, H.E.N., A.S.; Writing-original draft, H.E.N. and A.M.; Writing-review and editing, A.M., H.E.N., A.S. All authors have read and agreed to the published version of the manuscript.

Funding: This research was funded by The Natural Sciences and Engineering Research Council of Canada (NSERC) and Divert NS grant to the second author.

Data Availability Statement: All data, models, and code generated or used during the study appear in the submitted article.

Acknowledgments: The authors acknowledge the technical support received at Dalhaousie University for the conducted laboratory testing as well as the support received at Western University for the simple shear tests.

Conflicts of Interest: The authors declare that they have no known competing financial interests or personal relationships that could have appeared to influence the work reported in this paper.

\section{References}

1. Standard Practice for Use of Scrap Tires in Civil Engineering Applications; ASTM, D6270; ASTM: Conshohocken, PA, USA, 2008.

2. Mahgoub, A.; El Naggar, H. Using TDA underneath shallow foundations: Simplified design procedure. Int. J. Geotech. Eng. 2019, 1-15. [CrossRef]

3. Mahgoub, A.; El Naggar, H. Using TDA as an Engineered Stress-Reduction Fill over Preexisting Buried Pipes. J. Pipeline Syst. Eng. Pr. 2019, 10, 04018034. [CrossRef]

4. Mahgoub, A.; El Naggar, H. Coupled TDA-Geocell Stress-Bridging System for Buried Corrugated Metal Pipes. J. Geotech. Geoenvironmental Eng. 2020, 146, 04020052. [CrossRef]

5. Mahgoub, A.; El Naggar, H. Innovative Application of Tire-Derived Aggregate around Corrugated Steel Plate Culverts. J. Pipeline Syst. Eng. Pr. 2020, 11, 04020025. [CrossRef]

6. Mahgoub, A.; El Naggar, H. Shallow foundations on lightweight TDA backfill: Field tests and 3D numerical modelling. Comput. Geotech. 2020, 126, 103761. [CrossRef] 
7. Mills, B.; El Naggar, H.; Valsangkar, A. Chapter 22 in Volume 2 of Ground Improvement Case Histories. In North American Overview and Canadian Perspective on the Use of Tire Derived Aggregate in Highway Embankment Construction; Elsevier: Amsterdam, The Netherlands, 2015; pp. 635-655.

8. Ahn, I.S.; Cheng, L. Tire derived aggregate for retaining wall backfill under earthquake loading. Constr. Build. Mater. 2014, 57, 105-116. [CrossRef]

9. Moussa, A.; El Naggar, H. Numerical evaluation of buried wave barriers performance. Int. J. Geosynth. Ground Eng. 2020, 6, 1-13. [CrossRef]

10. Ni, P.; Qin, X.; Yi, Y. Use of tire-derived aggregate for seismic mitigation of buried pipelines under strike-slip faults. Soil Dyn. Earthq. Eng. 2018, 115, 495-506. [CrossRef]

11. Xiao, M.; Bowen, J.; Graham, M.; Larralde, J. Comparison of Seismic Responses of Geosynthetically Reinforced Walls with Tire-Derived Aggregates and Granular Backfills. J. Mater. Civ. Eng. 2012, 24, 1368-1377. [CrossRef]

12. Ahn, I.-S.; Cheng, L. Seismic analysis of semi-gravity RC cantilever retaining wall with TDA backfill. Front. Struct. Civ. Eng. 2017, 11, 455-469. [CrossRef]

13. Moussa, A.; El Naggar, H. Dynamic Characterization of Tire Derived Aggregates. J. Mater. Civ. Eng. 2021, 33. [CrossRef]

14. El Naggar, H.; Zahran, K.; Moussa, A. Effect of the Particle Size on the T.D.A. Shear Strength and Stiffness Parameters in Large-Scale Direct Shear Tests. Geotechnics 2021, 1, 1-17. [CrossRef]

15. El Naggar, H.; Zahran, K. Effect of the Particle Size on T.D.A. Shear Strength Parameters in Triaxial Tests. Buildings 2021, 11, 76. [CrossRef]

16. Zahran, K.; Naggar, H.E. Effect of Sample Size on T.D.A. Shear Strength Parameters in Direct Shear Tests. Transp. Res. Rec. 2020, 2674, 1110-1119. [CrossRef]

17. El Naggar, H.; Soleimani, P.; Fakhroo, A. Strength and Stiffness Properties of Green Lightweight Fill Mixtures. Geotech. Geol. Eng. 2016, 34, 867-876. [CrossRef]

18. Sparkes, J.; El Naggar, H.; Valsangkar, A. Compressibility and Shear Strength Properties of Tire-Derived Aggregate Mixed with Lightweight Aggregate. J. Pipeline Syst. 2019, 10, 4018031. [CrossRef]

19. Ashari, M.; El Naggar, H.; Martins, Y. Evaluation of the Physical Properties of TDA-Sand Mixtures. In Proceedings of the GeoOttawa 2017, the 70th Canadian Geotechnical Conference, Ottawa, ON, Canada, 1-4 October 2017.

20. El Naggar, H.; Ashari, M.; Mahgoub, A. Development of an Empirical Hyperbolic Material Model for TDA Using Large Scale Triaxial Testing. Int. J. Geotech. Eng. 2021, in press. [CrossRef]

21. Feng, Z.Y.; Sutter, K.G. Dynamic Properties of Granulated Rubber/Sand Mixtures. Geotech. Test. J. 2000, 23, 338-344. [CrossRef]

22. Hazarika, H.; Hyodo, M.; Yasuhara, K. Investigation of tire chips-sand mixtures as preventive measure against liquefaction. In Ground Improvement and Geosynthetics; ASCE: Reston, VA, USA, 2010; pp. 338-345.

23. Sarajpoor, S.; Kavand, A.; Zogh, P.; Ghalandarzadeh, A. Dynamic behavior of sand-rubber mixtures based on hollow cylinder tests. Constr. Build. Mater. 2020, 251, 118948. [CrossRef]

24. Cavallaro, A.; Lanzo, G.; Pagliaroli, A.; Maugeri, M.; Lo Presti, D. A comparative study on shear modulus and damping ratio of cohesive soil from laboratory tests. In Proceedings of the 3rd Int Symp on Deformation Characteristics of Geomaterials, Lisse, The Netherlands, 1 January 2003; pp. 257-265.

25. Subramaniam, P.; Subramaniam, P.; Banerjee, S.; Banerjee, S. Torsional Shear and Resonant Column Tests on Cement Treated Marine Clay. Indian Geotech. J. 2016, 46, 183-191. [CrossRef]

26. Cavallaro, A.; Grasso, S.; Maugeri, M. Dynamic Clay Soils Behaviour by Different Laboratory and in Situ Tests. In Soil Stress-Strain Behavior: Measurement, Modeling and Analysis; Springer: Berlin/Heidelberg, Germany, 2007; pp. 583-594.

27. Bedr, S.; Bedr, S.; Mezouar, N.; Mezouar, N.; Verrucci, L.; Verrucci, L.; Lanzo, G.; Lanzo, G. Investigation on shear modulus and damping ratio of Algiers marls under cyclic and dynamic loading conditions. Bull. Eng. Geol. Environ. 2019, 78, $2473-2493$. [CrossRef]

28. Standard Test Methods for the Determination of the Modulus and Damping Properties of Soils Using the Cyclic Triaxial Apparatus; ASTM, D3999; ASTM: Conshohocken, PA, USA, 2003.

29. Kowalska, M. Compactness of scrap tyre rubber aggregates in standard proctor test. Procedia Eng. 2016, 161, 975-979. [CrossRef]

30. Madhusudhan, B.R.; Boominathan, A.; Banerjee, S. Static and Large-Strain Dynamic Properties of Sand-Rubber Tire Shred Mixtures. J. Mater. Civil Eng. 2017, 29, 4017165. [CrossRef]

31. Anastasiadis, A.; Senetakis, K.; Pitilakis, K. Small-strain shear modulus and damping ratio of sand-rubber and gravel-rubber mixtures. Geotech. Geol. Eng. 2012, 30, 363-382. [CrossRef]

32. Senetakis, K.; Anastasiadis, A.; Pitilakis, K. Dynamic properties of dry sand/rubber (SRM) and gravel/rubber (GRM) mixtures in a wide range of shearing strain amplitudes. Soil Dyn. Earthq. Eng. 2012, 33, 38-53. [CrossRef] 